\title{
Upper Respiratory Tract Diseases in Athletes in Different Sports Disciplines
}

\author{
by \\ Anna Gałazka-Frantaํ, Edyta Jura-Szołtys², Wojciech Smótka ${ }^{3}$, Radosław Gawlik ${ }^{2}$
}

\begin{abstract}
Upper respiratory tract diseases in athletes are a very common medical problem. Training conditions in different sports disciplines increase the risk of upper respiratory disease. Epidemiological evidence suggests that heavy acute or chronic exercise is related to an increased incidence of upper respiratory tract infections in athletes. Regular physical exercise at high intensity may lead to transient immunosuppression due to high prevalence of allergic diseases in athletes. Regardless of the cause they can exclude athletes from the training program and significantly impair their performance. In the present work, the most common upper respiratory tract diseases in athletes taking into account the disciplines in which they most often occur were presented. The focus was laid on symptoms, diagnostic methods and pharmacotherapy. Moreover, preventive procedures which can help reduce the occurrence of upper respiratory tract disease in athletes were presented. Management according to anti-doping rules, criteria for return to training and competition as an important issues of athlete's health were discussed.
\end{abstract}

Key words: upper respiratory tract infection, allergy, immunity.

\section{Introduction}

Increased commercialization and competing for spectators and sponsors that have been observed in competitive sport in recent years result in much higher demands from athletes. Meeting the requirements that are currently set for athletes is possible owing to modern training methods, precise dietary strategies and advanced physiotherapeutic and medical care. In recent years, the athlete's immune system has been of special interest. Many authors seem to agree with the Nieman's theory that moderate exercise has an immunostimulatory effect, in contrast to intense exercise, which causes a temporary decrease in the immune system function, often called an open window for infection (Nieman, 2003). Stress hormones attenuate the response of specific immune cells. This is a short period (3-72 hours) following intense exercise when athletes are more

susceptible to develop infections (Nieman, 2003; Walsh et al., 2011). Previous research has confirmed that intense exercise necessary in competitive sport is related to a three times higher incidence of upper respiratory tract infections (URTI) (Spence et al., 2007). Moreover, a potential role of genetic variation in influencing the risk for upper respiratory tract infections in the athletic population has need identified, especially considering that single nucleotide changes (polymorphisms) in cytokine genes may influence the risk for URTI in some athletes (Cox et al., 2010). Zehsaz et al. (2010) suggested that these genetic analyses may have a predictive value in the identification of individuals who are more likely to experience recurrent infection when exposed to high physical stress.

Besides, athletes prone to infection are

1 - Chorzow Center of Pediatry and Oncology, Poland.

2- Chair and Clinical Department of Internal Diseases, Allergology and Clinical Immunology, Medical University of Silesia, Katowice, Poland

3. Clinical Department of Laryngology, School of Medicine in Katowice, Medical University of Silesia, Katowice, Poland. 
exposed to an increased risk for asthma and allergy. Several mechanisms can be implicated for this risk, which include the interplay between environmental training factors (allergens, temperature, air pollution) and athlete's personal risk factors, such as genetic susceptibility, neurogenic-mediated inflammation and epithelial sensitivity. Chronic and intense physical exercise may cause transient immunodepression with a preferential shift to a Th2 response, associated with the development of allergic reactions (Bonini et al., 2015).

Upper respiratory allergic diseases are an important group of upper respiratory tract diseases in athletes, since due to their long-lasting and persistent nature, they have a direct effect on athletic performance (Dijkstra and RobsonAnsley, 2011).

\section{Discussion}

\section{Allergic rhinitis}

Allergic rhinitis is a global problem, since it is estimated to affect $10-45 \%$ of the world's population (Bonini et al., 2006). Allergic rhinitis is a disease influenced by genetic and many environmental factors, in up to $50 \%$ patients nonallergic triggers are also involved (Bonini et al., 2006; Dykewicz and Hamilos, 2010).

According to numerous studies, allergic rhinitis is even more prevalent among athletes. In the study by Katelaris et al. (2000) including 216 athletes representing 12 Olympic disciplines, 56\% reported the history of conjunctivitis and rhinitis. In another study including 93 athletes from South Africa representing 8 disciplines, allergic rhinitis or conjunctivitis was observed in $21.5 \%$ of the subjects (Hawarden et al., 2002). Gelardi et al. (2012) studied a group of 74 swimmers, where $35 \%$ had positive skin prick tests with inhaled allergens, and $44 \%$ had symptoms in the upper respiratory tract.

ARIA (Allergic Rhinitis Impact on Asthma) report in 2008 changed the classification of allergic rhinitis from the time of exposure point of view (seasonal, perennial and occupational) to a symptomatic definition (intermittent allergic rhinitis and persistent allergic rhinitis) and severity characterization (mild or moderate-severe) (Bousquet et al., 2008). The seasonal and perennial rhinitis classification is still useful for diagnosis as well as immunotherapy treatment decision and can be used alongside the ARIA classification. The most frequent allergic triggers include inhalant allergens: house dust mites, pollens, animal dander and moulds. It has been shown that patients living in air polluted areas have more severe rhinitis and conjunctivitis symptoms (D'Amato and Cecchi, 2008). Allergic rhinitis is clinically characterised by itching, sneezing, rhinorrhoea, nasal blockage and is frequently accompanied by conjunctival symptoms (red eye, itching, swelling, lacrimation).

Allergic rhinitis in athletes is a big challenge for sport medicine physicians. Detailed diagnosis given based on a skin prick test, allergen specific IgE estimation or even allergen nasal provocation, allows one to identify a causative agent and to choose the most appropriate strategy of management.

Treatment of allergic rhinitis includes only causative methods such as allergen immunotherapy and symptomatic use of antihistamines, intranasal glucocorticosteroids, decongestants; it should balance efficacy of treatment, its safety, hazards involved in athletic performance as well as WADA rules. Moreover, decongestants fast reducing nasal blockage have many side effects (tachycardia, increased blood pressure) and their longer use ( $>5$ days) induces rhinitis medicamentosa.

Allergic rhinitis impairs physical performance in professional athletes affecting sleep, decreasing the ability to concentrate or reducing physical fitness (Katelaris et al., 2000). In order to protect athlete's health, training sessions and camps should be planned with regard to the pollen calendar for a given region. This would allow to decrease or even avoid symptoms of rhinitis or bronchial hyperresponsiveness, which usually lead to a sudden decrease in athletic performance. The 2000 Summer Olympic Games in Sydney were the first to be organised in early spring, i.e. at the time of the highest concentration of inhaled allergens in the air. Katalaris et al. (2000) sought to examine then pollen levels at the major Olympic venues providing a crucial source of information about allergens at the site and time of the competitions. It helped the doctors taking care of allergic athletes to develop a detailed protocol of behaviour to minimise the potential negative impact of allergic diseases on athletic performance. 
Immune response that starts in the nose may lead also to immune response in the lower respiratory tract. AR is often concurrent with asthma or it precedes its development. Between 19 and $38 \%$ of patients with allergic rhinitis have symptoms of asthma and about $80-90 \%$ of subjects with asthma have symptoms of allergic rhinitis (Bonini et al., 2006). In the group of athletes examined by Gelardi et al. (2012), 15\% of swimmers suffering from allergic rhinitis also had symptoms of asthma.

According to ARIA recommendations, each athlete with allergic rhinitis, additionally to allergy tests, should undergo spirometry, a bronchial hyperresponsiveness test and an exercise test in the environment similar to the one in which a particular sports discipline is practised (Bousquet et al., 2008) because allergic rhinitis increases the risk of asthma development up to 7fold.

\section{Exercised-induced rhinitis (EIR)}

It occurs in subjects with both allergic and non-allergic rhinitis (Alves et al., 2010; Togias et al., 1985). Exercise-induced rhinitis was defined as a fall in the peak nasal inspiratory flow above $20 \%$ from baseline during exercise (Alves et al., 2010). Exercise-induced symptoms include watery nasal discharge, post-nasal drip, sneezing, swelling of nasal mucosa, eye and nose itching as well as lacrimation. The pathomechanism of exerciseinduced rhinitis is not known. Possible factors include increased tension in cholinergic fibres, NANC and increased secretion of inflammatory mediators of histamine, bradykinin, prostaglandin D2 and TAME (Silvers and Poole, 2006; Togias et al., 1985). According to Silvers and Poole (2006), these symptoms most frequently occur during the winter season (a skier's nose) and in athletes training outdoors. The above-mentioned symptoms are not very harmful to health, although they are burdensome and irritating for athletes and may therefore influence their performance. Literature does not say much about EIR (Alves et al., 2010; Silvers and Poole, 2006).

Subjects with EIR can be relieved using antihistamines or local ipratropium in the form of nasal inhalation.

\section{Risk factors of rhinitis in athletes}

Increased minute ventilation

Resting ventilation in a healthy subject is $8 \mathrm{l} / \mathrm{min}$ and increases to $20-30 \mathrm{l} / \mathrm{min}$ at moderate intensity activities. Intense exercise may elevate ventilation even up to $200 \mathrm{l} / \mathrm{min}$ (Lumme et al., 2003). Significantly increased minute ventilation during extreme exercise makes athletes more susceptible to seasonal and year-round allergens in comparison with the remaining population.

Cold air

Cold air inhaled by hockey players increases the amount of inflammatory cells (granulocytes and macrophages) in the respiratory tract (Larsson et al., 1998). Moreover, hockey players are in contact with carbon monoxide, nitrogen monoxide and nitrogen dioxide contained in the air of sports facilities (produced by ice cleaning machines). A study conducted by Thunqvist et al. (2002) showed that children playing hockey in facilities with an increased $\mathrm{N}_{2} \mathrm{O}$ content (mean concentration 510 $\mathrm{ug} / \mathrm{m} 3$ ) more often suffered from symptoms of rhinitis and wheezing respiration in comparison with children playing in facilities where the concentration of this gas was low (mean 89 $\mathrm{ug} / \mathrm{m} 3)$.

\section{Chlorine compounds}

Chlorine compounds are a crucial factor for development of rhinitis in swimmers. The highest concentration of these compounds is 10 $\mathrm{cm}$ above the water surface. Moreover, in the course of the breathing process, the upper respiratory tract is accessed by micro aerosol, which is very irritating and dries the respiratory mucosa adding a hypoosmotic effect. A study by Gelardi et al. (2012) conducted among swimmers showed that the most frequent type of rhinitis was AR, which occurred in $44 \%$ of athletes. However, $35 \%$ of swimmers had neutrophilic rhinitis. In contrast to eosinophil infiltration, which is typical of allergic diseases, neutrophil infiltration usually means prolonged contact with a damaging factor which in effect leads to development of inflammation. After using a nose clip for 4 weeks, Gelardi et al. (2012) observed a decrease in neutrophil infiltration in the nasal smear and also a decrease in symptoms of $\mathrm{AR}$ in athletes. Bougault et al. (2010) found in a study conducted with swimmers that $74 \%$ of the respondents reported symptoms of allergic rhinitis, compared to $40 \%$ in the control group. Additionally, the majority of swimmers reported significant deterioration of the quality of life caused by rhinitis. They also observed that a 2-week break in 
swimming resulted in a reduction of the nasal symptoms and improvement in the quality of life to the level of the control group (Bougault et al., 2010). In swimmers who had stopped high-level training, a reduced bronchial hyperreactivity and asthma symptoms were observed, whereas swimmers who remained active reported aggravation of these symptoms (Helenius et al., 2002). This suggests the reversibility of airway inflammatory changes.

The presence of nasal secretion disturbs the basic functions of nasal cavities, i.e. air cleaning, heating and humidifying (Bonini et al., 2006). Additionally, breathing through the nose becomes impossible, so breathing through the mouth is employed (at rest and at moderate exercise). At the same time, the lower respiratory tract is accessed by large amounts of air without being cleaned, warmed or humidified, which in turn may lead to bronchial hyperresponsiveness (Hendrik et al., 2011).

\section{Effects of rhinitis on athletes performance}

1. Effect on concentration - blowing and wiping one's nose every several minutes makes it impossible to maintain concentration at a stable level.

2. Nasal obturation leads to sleeping disorders which in turn cause persistent fatigue, having a negative effect on cognitive functions and reflexes, i.e. increasing reaction time.

3. Nasal secretion and swelling directly impair ventilation during exercise and at the same times disable normal breathing dynamics.

4. Impairment of visual coordination induced by allergic conjunctivitis is often concurrent with allergic rhinitis.

\section{Rhinosinusitis}

Rhinosinusitis is the inflammation of the nose and paranasal sinuses. Symptoms are nasal blockage, nasal discharge, facial pain and an impaired sense of smell. Treatment should be based on severity of symptoms. In common cold, symptomatic treatment such as decongestants, nasal saline irrigation and analgesics is used. If viral rhinosinusitis is complicated by acute bacterial infection (discoloured discharge, severe local pain, fever), topical steroids and antibiotics should be applied. It has been proposed that a daily dose of 5000 IU vitamin D3 supplementation has a beneficial effect on up-regulating the expression of secretory immunoglobulin $\mathrm{A}$ in athletes during a winter training period and could improve resistance to respiratory infections (He et al., 2014).

Rhinosinusitis is the most frequent among athletes practising water sports, i.e. swimmers, divers, water polo players and surfers. Elite athletes are even at a higher risk of developing this condition. Frequent changes in pressure are an additional factor contributing to paranasal sinus mucosal hypertrophy. Sonmez et al. (2011) included in their study 79 divers and a control group. Using magnetic resonance imaging the effect of prolonged episodes of pressure changes during diving on sinus mucosal hypertrophy was assessed. Sinus mucosal hypertrophy was observed in $41.8 \%$ of the divers and $22.8 \%$ of the control group (Sonmez et al., 2011). Obstruction which occurs in the connections between sinuses and nasal cavity resulting from rhinitis, sinusitis or deviated nasal septum leads to the situation when pressure between these two structures cannot be equalised during diving. This may lead to barotrauma. This condition is manifested with a sudden pain in sinuses, bloody secretion from the nose or nasal bleeding.

Rhinosinusitis is an absolute contraindication for diving. Athletes with sinusitis additionally suffer from recurrent headaches, which also have a damaging effect on training regularity and athlete's performance.

\section{Vocal cord dysfunction}

In literature, vocal cord dysfunction (VCD) is defined as paradoxical vocal fold motion that leads to obturation of airways (Morris et al., 2006). The correlation between VCD and asthma is not clear. A study conducted by Yelken et al. (2009) showed VCD occurrence in 19\% of 96 examined asthmatic patients and only in $5 \%$ of a 40 -member control group. Symptoms of vocal cord dysfunction include laryngeal inspiratory wheezing (stridor), tightness in the throat, increased excitation and sudden dyspnoea occurring especially during exercise (Wilson et al., 2009). Vocal cord dysfunction may have various forms, from cough and mild dyspnoea that regresses spontaneously after 1-2 min to severe ventilatory disturbances. A clinical picture of VCD often resembles exercise-induced bronchoconstriction and it may also accompany exercise-induced asthma.

VCD occurs both in athletes practising 
recreational and competitive sport. The latter group constitutes the majority of those affected by VCD. A study conducted on 370 athletes practising mainly winter sports (cross-country skiers, biathletes, ice-skaters, ice-hockey players, canoeists) revealed exercised-induced bronchoconsrtiction (EIB) in $30 \%$ of the athletes and laryngeal inspiratory stridor in $5.1 \%$ of the athletes (Rundel and Spiering, 2003). The majority of subjects suffering from stridor (52\%) had a history of exercise-induced asthma (Rundel and Spiering, 2003). The problem occurred more often in athletes training outdoors $(8.3 \%)$ than in those training indoors $(2.5 \%)$, which may confirm the effect of cold, dry air on the development of symptoms (Rundel and Spiering, 2003). VCD is more frequent among women aged 20-40 (Rundel and Spiering, 2003). The incidence of this condition is most probably underestimated, since numerous athletes with vocal cord dysfunction are also diagnosed with exercise-induced hyperreactivity of the bronchial tree and are often treated only with antihistamines that are ineffective for this disease entity (Wilson et al., 2009).

In case of atypical asthma symptoms or when asthma is difficult to control, one should always consider VCD as a potential cause of reported problems.

Since there are no specific diagnostic tests for this condition, the gold standard in VCD diagnosis is revealing an occlusion of anterior vocal cords in anterior laryngoscopy or videobronchoscopy (Sullivan et al., 2001).

If the VCD cause is not organic, the best effects are achieved with phoniatric rehabilitation, cooperation with a logopedist, muscle relaxation techniques, breathing exercises, psychotherapy and behavioural therapy (Wilson et al., 2009). Moreover, special importance is attached to breathing control and the skill of diaphragmatic breathing (Sullivan et al., 2001).

\section{Otitis externa}

Similarly to rhinosinusitis, ear health problems occur most frequently in athletes having contact with water. Otitis externa affects about $10 \%$ of the population and the main risk factors include warm and humid climate and frequent contact with water. This disease entity is commonly known as a swimmer's ear because the risk of otitis externa in swimmers is 5 times higher than in subjects who do practice this sports discipline (Hoadley and Knight, 1975).

The presence of water in the ear canal causes skin maceration, damages the protective barrier and creates conditions for the development of bacteria (Wang et al., 2005). Bacterial infection is typically the underlying cause of this condition and it is responsible for $98 \%$ of all cases of otitis externa in the USA (Roland and Stroman, 2002). In most cases the responsible pathogens are Pseudomonas aeruginosa and Staphylococcus aureus (Rosenfeld et al., 2014). A typical symptom of otitis is pain, especially while touching the earlobe, also swelling, itching, presence of secretion in the auditory tube and occasionally hearing loss. Treatment involves management of pain, removal of debris from the external auditory canal, administration of topical antibiotics and steroids to control edema and infection (Wang MC et al., 2005).

\section{Practical implications}

Treatment of allergic upper respiratory tract diseases in athletes in regard to antidoping rules

World Anti-Doping Agency (WADA) permits most agents used in treatment of allergic respiratory tract diseases to be used also by competitive athletes.

The list of substances prohibited in athletes includes:

- ephedrine and methylephedrine - if the urine concentration exceeds $10 \mathrm{ug} / \mathrm{ml}$.

- pseudoephedrine - if the urine concentration exceeds $150 \mathrm{ug} / \mathrm{ml}$

Local administration (e.g. nasal, ophthalmologic) of epinephrine (adrenaline) or co-administration with local anaesthetic agents is not prohibited.

Regardless of the substances prohibited by WADA, caution should be exercised when using these agents that due to their adverse reactions (antihistamines) could have a negative effect on athletes' reflexes (WADA, 2014).

\section{Return to play - returning to sport participation at a premorbid level}

We must differentiate between a return to training and the possibility of taking part in competition. Criteria for the latter are stricter and require full recovery and a perfect health state of the athlete. Apart from good results of a physical 
examination, normalization of CRP (C Reactive Protein) and leukocytosis is essential.

Current recommendations on training of athletes with symptoms of upper respiratory tract infections are as follows:

1. Athletes with symptoms limited to the upper respiratory tract (a sore throat, a runny nose, no fever) - moderate training below $70 \%$ of the maximum heart rate and changing the training schedule from endurance to skill training

2. Athletes with systemic symptoms (fatigue, fever $>38^{\circ} \mathrm{C}$, a cardiac rate at rest increased by $10 / \mathrm{min}$ ) - a ban on physical activity until regression of symptoms followed by a gradual return to training.

Initially, training with a moderate load (aerobic) increased every day until the maximal load is achieved. Depending on the type of infection, the scheduled period of returning to training with a maximal load may range from 3-5 days to 3 weeks. It must be emphasised that pressure exerted on the athlete to accelerate their return to high-level performance may be very harmful to their health and may postpone full recovery of their performance (Scharhag and Meyer, 2014).

Due to an increasing incidence of allergic diseases, Bonini et al. (2009) developed a reliable questionnaire for screening allergy in the population of athletes. The AQUA questionnaire is currently recommended in order to pinpoint the athletes from the risk group and to include them in the interdisciplinary care (Lumme and Haahtela, 2003). Athletes from the group of the risk of allergic diseases should be educated about the necessity of prevention involving avoidance of allergens, and in case of upper respiratory tract infections about the purposefulness of limiting intense physical activity.

Upper respiratory diseases are common in elite athletes and may negatively impact athletic performance and recovery. Because of potential risk of allergic rhinitis for asthma, an early recognition, diagnosis and treatment are very important. In non-atopic athletes as well as in atopic ones, intense training in unfavourable environments (such as cold air, chlorinated swimming pools) can lead to an increase in respiratory symptoms. When possible, athletes should refrain from intense training or competition for minimum 3 days after an infection or exacerbation. Treatment of allergic upper respiratory tract diseases and infections in athletes should follow the antidoping rules of WADA. Athletes identified with upper respiratory tract diseases should be provided with recommendations tailored to meet their specific needs.

\section{References}

Alves A, Martins C, Delgado L, Fonseca J, Moreira A. Exercise-induced rhinitis in competitive swimmers. Am J Rhinol Allergy, 2010; 24: 114-117

Bonini S, Bonini M, Bousquet J, Brusasco V, Canonica GW, Carlsen KH, Corbetta L, Cummiskey J, Delgado L, Del Giacco SR, Haahtela T, Jaeger S, Moretti C, Palange P, Passalacqua P, Passali D, Pedersen BK, Popov T, Rasi G, Ventura MT, Vignola AM. Rhinitis and asthma in athletes: an ARIA document in collaboration with GA2LEN.

Allergy, 2006; 61: 681 -692

Bonini M, Braido F, Baiardini I, Del Giacco S, Gramiccioni C, Manara M, Tagliapietra G, Scardigno A, Sargentini V Brozzi M, Rasi G, Bonini S. AQUA: Allergy Questionnaire for Athletes. Development and validation. Med Sci Sports Exerc, 2009; 41: 1034-1041

Bonini M1, Gramiccioni C, Fioretti D, Ruckert B, Rinaldi M, Akdis C, Todaro A, Palange P, Carlsen KH, Pelliccia A, Rasi G, Bonini S; AIDA and the Italian Unit of the GA2LEN Olympic Study. Asthma, allergy and the Olympics: a 12-year survey in elite athletes. Curr Opin Allergy Clin Immunol, 2015; 15: 184-92

Bougault V, Turmel J, Boulet LP. Effect of intense swimming training on rhinitis in high-level competitive 
swimmers. Clin Exp Allergy, 2010; 40: 1238-1246

Bousquet J, Khaltaev N, Cruz AA, Denburg J, Fokkens WJ, Togias A, Zuberbier T, Baena-Cagnani CE, Canonica GW, van Weel C, Agache I, Aït-Khaled N, Bachert C, Blaiss MS, Bonini S. Allergic rhinitis and its impact on asthma (ARIA) 2008 update (in collaboration with the World Health Organization, GA(2) LEN and AllerGen). Allergy, 2008; 63: 8- 160

Cox AJ, Gleeson M, Pyne DB, Callister R, Fricker PA, Scott RJ. Cytokine gene polymorphisms and risk for upper respiratory symptoms in highly-trained athletes. Exerc Immunol Rev, 2010; 16: 8-21

D'Amato G, Cecchi L. Effects of climate change on environmental factors in respiratory allergic diseases. Clin Exp Allergy, 2008; 38: 1264-1274

Dijkstra HP, Robson-Ansley P. The prevalence and current opinion of treatment of allergic rhinitis in elite athletes. Curr Opin Allergy Clin Immunol., 2011; 11: 103-8

Dykewicz M S, Hamilos DL. Rhinitis and sinusitis. J Allergy Clin Immunol, 2010; 125: 103-111

Gelardi M, Ventura MT, Fiorella R, Fiorella ML, Russo C, Candreva T, Carretta A,

Passalacqua G. Allergic and non-allergic rhinitis in swimmers: clinical and cytological

aspects. Br J Sports Med, 2012; 46: 54-58

Hawarden D, Baker S, Toerien A, Prescott R, Leaver R, Potter PC, Derman W. Aero-allergy in South African Olympic athletes. S Afr Med J, 2002; 92: 355-356

He CS, Fraser WD, Tang J, Brown K, Renwick S, Rudland-Thomas J, Teah J, Tanqueray E, Gleeson M. The effect of 14 weeks of vitamin D3 supplementation on antimicrobial peptides and proteins in athletes. J Sports Sci, 2015; 10: 1-8

Helenius I, Rytilä P, Sarna S, Lumme A, Helenius M, Remes V, Haahtela T. Effect of continuing or finishing high-level sports on airway inflammation, bronchial hyperresponsiveness, and asthma: a 5-year prospective follow-up study of 42 highly trained swimmers. J Allergy Clin Immuno, 2002; 109: 962 -968

Hendrik P, Dijkstra and Paula Robson-Ansley. The prevalence and current opinion of treatment of allergic rhinitis in elite athletes. Current Opinion in Allergy and Clinical Immunology, 2011; 11: 103-108

Hoadley AW, Knight DE. External otitis among swimmers and non swimmers. Arch Environ Health, 1975; 30: $445-448$

Katelaris C, Carrozzi F, Burke T, Byth K. A springtime Olympics demands special consideration for allergic athletes. J Allergy Clin Immunol, 2000; 106: 260-266

Larsson K, Tornling G, Gavhed D, Muller-Suur C, Palmberg L. Inhalation of cold air increases the number of inflammatory cells in the lungs in healthy subjects. Eur Respir J, 1998; 12: 825-830

Lumme A, Haahtela T, Ounap J, Rytilä P, Obase Y, Helenius M, Remes V, Helenius I. Airway inflammation, bronchial hyperresponsiveness and asthma in elite ice hockey players. Eur Respir J, 2003; 22: 113-117

Morris MJ, Allan PF, Petkins PJ. Vocal cord dysfunction: etiologies and treatment. Clinical Pulmonary Medicine, 2006; 13: 73-86

Nieman DC. Current perspective on exercise immunology. Curr Sports Med Rep, 2003; 2: 239 -242

Roland PS, Stroman DW. Microbiology of acute otitis externa. Laryngoscope, 2002; 112: 1166-1177

Rosenfeld RM, Schwartz SR, Cannon CR, Roland PS, Simon GR, Kumar KA, Huang WW, Haskell HW, Robertson PJ. Clinical practice guideline: acute otitis externa. Otolaryngol Head Neck Surg, 2014; 150: 161-168

Rundell K, Spiering B. Inspiratory stridor in elite athletes. Chest, 2003; 123: 468-474

Scharhag J, Meyer T. Return to play after acute infectious disease in football players. J Sports Sci, 2014; 32: 1237-1242

Silvers WS, Poole JA . Exercise-induced rhinitis: a common disorder that adversely affects allergic and nonallergic athletes. Ann Allergy Asthma Immunol, 2006; 96: 334-340

Spence L, Brown WJ, Pyne DB, Pyne DB, Nissen MD, Sloots TP, McCormack JG, Locke AS, Fricker PA. 
Incidence, etiology, and symptomatology of upper respiratory illness in elite athletes. Med Sci Sports Exerc, 2007; 39: 577-586

Sonmez G, Uzun G, Mutluoglu M, Toklu AS, Mutlu H, Ay H, Yildiz S. Paranasal sinus mucosal hypertrophy in experienced divers. Aviat Space Environ Med, 2011; 82: 992-994

Sullivan M, Heywood B, Beukelman D. A treatment for vocal cord dysfunction in female athletes: An outcome study. Laryngoscope, 2001; 111: 1751-1755

Thunqvist P, Lilja G, Wickman M, Pershagen G. Asthma in children exposed to nitrogen dioxide in ice arenas. Eur Respir J, 2002; 20: 646-650

Togias AG, Naclerio RM, Proud D, Fish JE, Adkinson NF Jr, Kagey-Sobotka A, Norman PS, Lichtenstein LM. Nasal challenge with cold, dry air results in release of inflammatory mediators. J Clin Invest, 1985; 76: 1375-1381

WADA. The World Anti-doping Code. The 2014 Prohibited List. International Standard http://www.wadaama.org

Walsh NP, Gleeson M, Pyne DB, Nieman DC, Dhabhar FS, Shephard RI, Oliver SI Bermon S, Kajeniene A. Position statement. Part two: Maintaining immune health. Exerc Immunol Rev, 2011; 17: 64-103

Wang MC, Liu CY, Shiao AS, Wang T. Ear Problems in Swimmers. J Chin Med Assoc, 2005; 68: 347-352

Wilson JJ, Theis SM, Wilson.EM. Evaluation and management of vocal cord dysfunction in the athlete. Curr. Sports Med. Rep, 2009; 8: 65-70

Yelken K, Yilmaz A, Guven M, Eyibilen A, Aladag I. Paradoxical vocal cord motion dysfunction in asthma patients. Respirology, 2009; 14:729-733

Zehsaz F, Farhangi N, Monfaredan A, Tabatabaei Seyed M. IL-10 G-1082A gene polymorphism and susceptibility to upper respiratory tract infection among endurance athletes. J Sports Med Phys Fitness, 2015; 55: 128-34

\section{Corresponding author:}

\section{Radosław Gawlik, MD, PhD}

Chair and Clinical Department of Internal Diseases,

Allergology and Clinical Immunology

Medical University of Silesia, Katowice, Poland

ul. Ceglana 35

40-952 Katowice

Poland

Phone/fax: +48323581435

E-mail: radwags@poczta.onet.pl 